(2014). Labour Market Driven Learning Analytics. Journal of Learning Analytics, 1(3), 207-210.

\title{
Labour Market Driven Learning Analytics
}

\author{
Vladimer Kobayashi, Stefan T. Mol, and Gábor Kismihók \\ Center of Job Knowledge Research \\ University of Amsterdam, Netherlands \\ v.Kobayashi@uva.nl
}

\begin{abstract}
This paper briefly outlines a project about integrating labour market information in a learning analytics goal-setting application that provides guidance to students in their transition from education to employment.
\end{abstract}

KEYWORDS: Labour market information, goal-setting, learning analytics, education-toemployment

\section{MOTIVATION}

A contemporary trend being felt worldwide is the high level of youth unemployment along with a shortage of crucial job skills (Mourshed, Patel, \& Suder, 2014). In Europe, employers have acknowledged that the primary reason for the high number of entry-level vacancies is the scarcity of required skills among job-seekers (Mourshed et al., 2014). This mismatch of skills and jobs not only results in business and economic losses but also in job instability, cognitive decline, and lower occupational status on the part of individuals (Wolbers, 2003). Employers must engage with education providers to implement information-driven programs for the successful transition of students from education to the labour market (Olson, 1997). Students must partake in the planning of their education years to acquire a sense of ownership for their decisions and actions (Mithaug, Agran, Martin, \& Wehmeyer, 2002). The aim of this research is to help facilitate the transfer of students from education to employment by exposing them to accurate and timely labour market information (Stigler, 1962). We specifically aim to develop an application that presents derived labour market information alongside student activity/performance data to guide students as they navigate toward their desired employment.

\section{LITERATURE REVIEW}

Many efforts in education research centre on the new field of learning analytics that uses student data to understand and improve the student learning process. Universities are implementing technologies to increase student engagement, awareness (Pohl, Bry, Schwarz, \& Gottstein, 2012), and motivation (Silius et al., 2010), support collaborative learning (Dawson, Bakharia, \& Heathcote, 2010), and enable the delivery of recommendations (Rojas, García, \& Kloos, 2011). Moreover, educational data scientists are building mathematical and statistical models to identify students at risk of failure (Essa \& Ayad, 2012) or dropping out (Wolff, Zdrahal, Nikolov, \& Pantucek, 2013). However, the measured effects are confined 
(2014). Labour Market Driven Learning Analytics. Journal of Learning Analytics, 1(3), 207-210.

only to specific learning outcomes, such as enhancing cognitive skills and behavioural elements, and do not have a verifiable impact on student employment opportunities upon graduation.

\section{METHOD}

The primary objective of this research is to improve our understanding of person-job fit through the lens of concomitant skill development. First, it investigates the process that governs the successful transition from education to employment by analyzing education-to-labour market trajectory data. Second, an application that helps students to set, plan, and realize their employment objectives is developed. Labour market data will be analyzed to extract information that may impact student planning. Target data sources include longitudinal education-to-employment data of alumni, job knowledge data mined from vacancies and professional interviews, and job and wage trends and indicators. The aggregate analysis of labour data sources alongside student performance and behavioural data are presented to the user in a software solution the main functionality of which is to help students set, manage, and achieve learning goals.

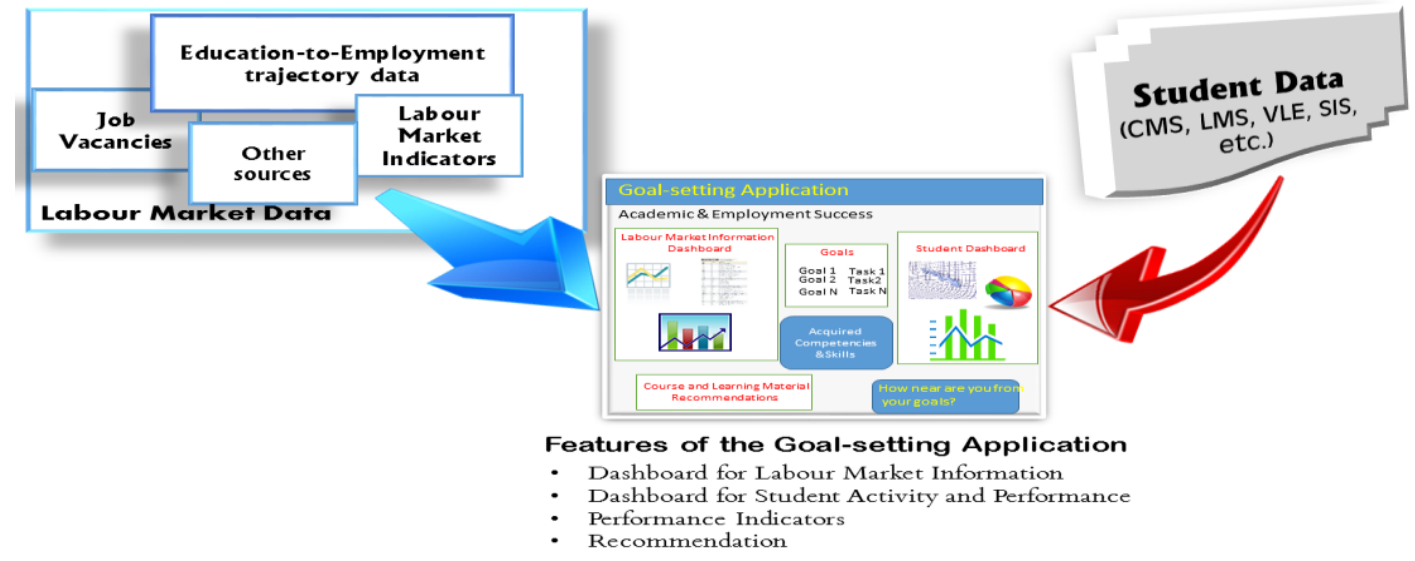

Figure 1. A goal-setting program to aid students in their journey from education to employment.

The proposed software solution is a goal-setting program in which students can specify goals (e.g., learning goals as subgoals of more distant career goals) and is developed according to design-based research. Ideally, students adopt goals based on knowledge about the labour market and recommendations of school advisors. The application will also serve as a platform where students can access relevant labour market information, view progress and success indicators, and receive recommendations from course advisors. The recommendation capability is akin to the Degree Compass (Denley, 2012), which provides course and learning recommendations to push students toward their desired professions. 
(2014). Labour Market Driven Learning Analytics. Journal of Learning Analytics, 1(3), 207-210.

\section{RESULTS}

We are now in the process of obtaining data from alumni regarding education-to-employment trajectories and starting the analysis of online job vacancy data to obtain job information. The job information extraction algorithm classifies the sentences in English vacancies into job attributes and job activities. Preliminary results showed that the algorithm correctly categorizes the sentences with a cross-validated accuracy of $95 \%$ (base accuracy: $55 \%$ ). We collected and manually labelled online job vacancy datasets for the validation procedure. The actual labels were compared to the predicted labels and accuracies were computed. The information can be used to determine current demand for skills and the type of education and experience companies are looking for in job-seekers. Alongside data analysis, we are compiling software requirements for the goal-setting application. The next step is to prototype the application and solicit user opinions and demands.

The deliverables for this research are the knowledge created from the analysis of labour market data and the goal-setting application. The application includes dashboards that illustrate labour market knowledge and student activity and performance data. It also has messaging functionality through which course advisors can deliver feedback and recommendations (see Figure 1).

\section{CONTRIBUTION TO LEARNING ANALYTICS}

This research expands the impact of learning analytics beyond the educational setting by helping students to navigate the education-to-employment pathway using a goal-setting application as a compass. The principles and techniques of learning analytics are suitable for this research since the tasks not only require analytical methods but also an examination of learning constructs and educational theories.

\section{ACKNOWLEDGEMENTS}

We are grateful for the financial support of the Eduworks Marie Curie Initial Training Network Project (PITN-GA-2013-608311) of the European Commission's 7th Framework Programme.

\section{REFERENCES}

Dawson, S., Bakharia, A., \& Heathcote, A. (2010). SNAPP: Realising the affordances of real-time SNA within networked learning environments. In Handbook and abstracts for the seventh International Conference on Networked Learning 2010: A research based conference on networked learning in higher education and lifelong learning (pp. 125-134). Lancaster, UK: University of Lancaster.

Denley, T. (2012). Austin Peay State University: Degree compass. EDUCAUSE Review Online. Retrieved from http://www.Educause.Edu/ero/article/austin-Peay-State-University-Degree-Compass. 
(2014). Labour Market Driven Learning Analytics. Journal of Learning Analytics, 1(3), 207-210.

Essa, A., \& Ayad, H. (2012). Student success system: Risk analytics and data visualization using ensembles of predictive models. Proceedings of the 2nd International Conference on Learning Analytics and Knowledge (pp. 158-161). New York: ACM.

Mithaug, D. K., Agran, M., Martin, J. E., \& Wehmeyer, M. L. (2002). Self-determined Learning Theory: Construction, Verification, and Evaluation. London: Routledge.

Mourshed, M., Patel, J., \& Suder, K. (2014). Education to employment: Getting Europe's youth into work. Washington, DC: McKinsey Center for Government.

Olson, L. (1997). The school-to-work revolution: How employers and educators are joining forces to prepare tomorrow's skilled workforce. Cambridge, MA: Da Capo Press.

Pohl, A., Bry, F., Schwarz, J., \& Gottstein, M. (2012). Sensing the classroom: Improving awareness and self-awareness of students in Backstage. In 15th International Conference on Interactive Collaborative Learning (ICL) (pp. 1-8). doi:10.1109/ICL.2012.6402110

Rojas, I. G., García, R. M. C., \& Kloos, C. D. (2011). Orchestration and feedback in lab sessions: Improvements in quick feedback provision. In C. D. Kloos, D. Gillet, R. M. C. García, F. Wild, \& M. Wolpers (Eds.), Towards Ubiquitous Learning (pp. 424-429). Berlin/Heidelberg: Springer .

Silius, K., Miilumaki, T., Huhtamaki, J., Tebest, T., Merilainen, J., \& Pohjolainen, S. (2010). Students' motivations for social media enhanced studying and learning. Knowledge Management \& ELearning: An International Journal (KM\&EL), 2(1), 51-67.

Stigler, G. J. (1962). Information in the labor market. The Journal of Political Economy, 70(5), 94-105.

Wolbers, M. H. J. (2003). Job mismatches and their labour-market effects among school-leavers in Europe. European Sociological Review, 19(3), 249-266. doi:10.1093/esr/19.3.249

Wolff, A., Zdrahal, Z., Nikolov, A., \& Pantucek, M. (2013). Improving retention: Predicting at-risk students by analysing clicking behaviour in a virtual learning environment. Proceedings of the $3 \mathrm{rd}$ International Conference on Learning Analytics and Knowledge (pp. 145-149). New York: ACM. doi:10.1145/2460296.2460324 